\title{
Construction and Sequencing of Dense Granular14 (GRA14) Gene of Toxoplasma gondii (RH) in Expression Prokaryotic Plasmid PET32a: A Preliminary Study in Vaccine Production
}

\author{
Mohammad Ashrafi ${ }^{1}$, Hossein Sobati ${ }^{2 *}$, Seyyed Javad Seyyed Tabaei ${ }^{3}$ \\ ${ }^{1}$ Department of Parasitology and Mycology, Faculty of Medicine, Baqiyatallah University of Medical Sciences, Tehran, Iran \\ ${ }^{2}$ Health Research Center, Life Style Institute, Baqiyatallah Universityof Medical Sciences, Tehran, Iran \\ ${ }^{3}$ Department of Parasitology and Mycology, Shahid Beheshti University of Medical Sciences, Tehran, Iran
}

Corresponding Author: Hossein Sobati, Health Research Center, Life Style Institute, Baqiyatallah University of Medical Sciences, Tehran, Iran. Tel: +98-21-82483417, Fax: +98-21-88620843, Email: sobatih@gmail.com

Received December 25, 2017; Revised March 1, 2018; Accepted March 8, 2018; Online Published June 20, 2018

\begin{abstract}
Introduction: Toxoplasma gondii is an obligatory intracellular protozoan parasite, which infects human beings. Since the current antigens used for diagnosis or vaccination are contaminated with non -parasitic material in which the parasite is grown, it is tried to produce recombinant antigens to design vaccines against toxoplasmosis, or make diagnostic kits. Choosing the type of antigen to produce recombinant vaccine or diagnostic kits is considerably important. The dense granule protein 14 (GRA14) gene is one of the excretorysecretary antigens of Toxoplasma which seems to be an appropriate candidate in production of recombinant vaccines and diagnostic kits. The current study aimed to clone GRA14 gene of $T$. gondii (RH) in a cloning vector for further production of dense granular proteins. Materials and Methods: Genomic DNA was isolated from tachyzoite of parasite by phenol chloroform method and gene fragment was amplified by polymerase chain reaction (PCR). The PCR products were ligated into restriction enzymes sites of pTG19-T cloning vector. Then transformed into Escherichia coli Top10 strain and screened by IPTG and X-Gal. Then recombinant plasmid confirmed by the colonyPCR and restriction enzyme digestion using Sacl and Notl was done followed by sequencing. After isolation of this gene from pTG19-T, it was subcloned into a prokaryotic expression plasmid (pET32a). The pET32a - GRA14 constructs were analyzed by PCR, restriction analysis and sequencing.

Results: Evaluation of PCR products by agarose gel electrophoresis and analysis of nucleotide sequencing of 1227 bp gene encoding the protein GRA14, revealed the complete homology with the recorded sequences in the gene bank. After enzyme restriction and electrophoresis a fragment about 1227 bp was separated from pET32a.

Conclusions: The result of this study showed that recombinant GRA14 Toxoplasma was constructed successfully and ready for future study which seems like the antigen is a suitable candidate to produce recombinant vaccine and diagnostic kit.

Keywords: Toxoplasma gondii; Dense Granule Antigen 14; Cloning, Subcloning

Citation: Ashrafi M, Sobati H, Seyyed Tabaei SJ. Construction and sequencing of dense granular14 (GRA14) gene of Toxoplasma gondii $(\mathrm{RH})$ in expression prokaryotic plasmid PET32a: a preliminary study in vaccine production. J Appl Biotechnol Rep. 2018;5(2):75-80. doi:10.29252/jabr.05.02.07.
\end{abstract}

\section{Introduction}

Toxoplasma gondii is an obligatory intracellular protozoan that causes toxoplasmosis disease. The life cycle of parasite is completed by cat and warm-blooded animals. ${ }^{1}$ In acute form of disease the parasite reproduced inside the host blood and other organ's cells and in chronic form of disease the parasite transforms to cysts. ${ }^{1}$ Toxoplasma may cause different clinical forms such as asymptomatic or sever symptoms like abortion, congenital defects and death. ${ }^{2}$ In spite of current strategies in vaccine production that are based on using living or non-living agents, it seems necessary using novel methods such as molecular methods to improve vaccine production and inhibiting of activation risk of organisms. ${ }^{3-5}$ The novel strategies in production of vaccine are based on production of recombinant antigens of microorganisms. ${ }^{6}$ Natural antigens of toxoplasma are used to identify parasite antibodies in commercial kits, and considering that the parasite is cultivated in living cell, the possible risk for contamination of parasite antigens with host-cell antigens may lead to diagnostic deviations and also the quality of this kind of antigens are not stable. ${ }^{7}$ Considering that the production of these recombinant antigens are possible and such antigens do not have deficiencies listed for natural antigens, so nowadays the production of these types of antigens are considered. ${ }^{8}$ Since the current antigens that are used for diagnosis or vaccination are contaminated with nonparasitic material in which the parasite is grown, a

Copyright (C) 2018 The Author(s). This is an open-access article distributed under the terms of the Creative Commons Attribution License (http:// creativecommons.org/licenses/by/4.0), which permits unrestricted use, distribution, and reproduction in any medium, provided the original work is properly cited. 
lot of efforts are made to produce recombinant antigens to design vaccine against toxoplasmosis or make diagnostic kits. ${ }^{9}$ Choosing the type of antigen to produce recombinant vaccine or diagnostic kits is considerably important because it should not be immunogene, trigger of cellular immunity response, proliferator of $\mathrm{T}$ lymphocytes and also be presented in most of the parasite life-cycle. ${ }^{10}$ Identification of a potential target gene or protein is an important step in developing a diagnostic method to detect a pathological agent.

Dense granule antigens (GRAs) which are involved in parasite survival and virulence are known to be potential and useful diagnostic markers. ${ }^{11}$ They are found abundantly in both tachyzoites and bradyzoites and make up most of the circulating antigens in the blood stream of an infected host which can be detected as early as a few hours post infection (acute phase). ${ }^{11,12}$ Dense granule (GRA) proteins are proteins with high immunogenicity ${ }^{13}$ and are also able to induce strong antibody responses during acute infection. GRA proteins were also found during the chronic stage of T. gondii infection. ${ }^{11,13}$ As a result, the immunogenicity and prolonged expression of GRA proteins make them one of the promising candidates for recombinant protein production. Therefore have higher potential to develop tools for laboratory diagnosis of toxoplasmosis. ${ }^{13,14}$ Hence, GRA proteins have been suggested as potential targets to diagnose $T$. gondii infection, ${ }^{12,15-18}$ and hereby continuous study of the proteins are essential. GRA14 a novel dense granule protein, which is secreted into the vacuole and traffics both the PVM and IVN. ${ }^{19}$ GRA14 is targeted to membranous structures within the vacuole known as the intravascular network and to the vacuolar membrane surrounding the parasite. ${ }^{19}$ It has an unexpected topology in the PVM with its $\mathrm{C}$ terminus facing the host cytoplasm and its $\mathrm{N}$ terminus facing the vacuolar lumen. ${ }^{20}$ GRA14 can be transferred between vacuoles during infection; a process is called intervacuolar transport. ${ }^{19}$ GRA14 colocalizes with other GRA proteins on PVM extensions, where GRA14positive extensions were found to connect neighboring PVs. ${ }^{19}$

GRA14 protein has 409 amino acids and its gene is about $1227 \mathrm{bp}$ and without introns. ${ }^{21}$ Regardless of the possible roles of GRA14, there is no study to clone and subclone GRA14 T. gondii in prokaryotes vector. ${ }^{22}$ In this work we describe the cloning of a new gene encoding a novel, GRA14 T. gondii for the first time in prokaryotic expression vector for further production of Dense Granular proteins. It could be used to reach completely expressed GRA14 and constructing of the vaccine or diagnostic kit.

\section{Materials and Methods}

Chemicals, Reagent and Kits

The polymerase chain reaction (PCR) cloning kit was purchased from Fermentas (Germany) and other kits were purchased from Qiagen (Germany). Restriction endonucleases were purchased from Fermentas, USA, also T4 DNA ligase, Taq polymerase, dNTP and protein weight markers were provided from the Roche Company (Germany). 5-Bromo-4-chloro- 3-indolyl $\beta$-D-galactopyranoside (X-gal) and Isopropyl- $\beta$-D-thiogalactopyranoside (IPTG) were purchased from the Sigma-Aldrich Corporation (Germany).
The Escherichia coli strain TOP1O (Invitrogen), plasmid pTG19-T (Vivantis, Canada) and pET32a(+) prokaryotes expression vector were provided from Invitrogen (Invitrogen, Carlsbad, USA) . All chemicals were obtained from Merck (Germany), Sigma-Aldrich (Germany) and HiMedia Corporations (India).

Production of Toxoplasma gondii Tachyzoites The RH strain of T. gondii was provided from parasitology department of Public Health Faculty, Shahid Beheshti University of Medical Sciences. Tehran, Iran. Tachyzoites were harvested from the peritoneal cavity of $\mathrm{BALB} / \mathrm{c}$ mice 3-4 day after intraperitoneal (ip) injection with $1 \times 10^{5}$ of parasite suspension in sterile phosphate-buffered saline (PBS; $\mathrm{pH}$ 7.4) containing $100 \mathrm{IU} / \mathrm{mL}$ penicillin and $100 \mathrm{mg} / \mathrm{mL}$ streptomycin ${ }^{23,24}$ for lysate preparation and DNA extraction and stored at $-70^{\circ} \mathrm{C}$.

DNA Extraction and PCR Amplification of GRA14 Gene Standard methods were used for DNA extraction. ${ }^{25,26}$ Genomic DNA of T. gondii RH strain was extracted using the QIAamp DNA Mini Kit (Qiagen, Germany) according to the manufacturer's instructions. DNA extraction products were electrophoresed in 1\% agarose gel and then photographed. A pair of primers based on the full protein-coding region of the T. gondii GRA14 gene sequence (Accession number FJ015061.1) was designed by the DNASIS primer designer software (version 2.6) with SacI and NotI restriction sites at 5' end of forward and reverse primers, respectively.

The sequences were GRA14F:5'GAGCTCATGCAGGCGATAGCG-3' and GRA14R: 5'-GCGGCC GCCTATTCGCTTGGTCTCTG -3' (Bioneer, South Korea). Also, the PCR reaction was performed in a total volume of $50 \mu \mathrm{L}$ containing: $100 \mathrm{ng} \mathrm{DNA}, 1 \mu \mathrm{L}$ forward and reverse primers at $25 \mathrm{pM}, 50 \mathrm{mM} \mathrm{Mgcl}_{2}, 200 \mu \mathrm{M}$ dNTP, 10X PCR buffer, and $2.5 \mathrm{U}$ Taq polymerase (Germany).

The PCR conditions were as follows: initial denaturation at $94^{\circ} \mathrm{C}$ for 5 minutes; denaturation at $94^{\circ} \mathrm{C}$ for 1 minute, annealing at $62^{\circ} \mathrm{C}$ for 30 seconds and extension at $72^{\circ} \mathrm{C}$ for 45 seconds, which were followed by 30 cycles and a final extension at $72^{\circ} \mathrm{C}$ for 5 minutes in a thermal cycler. The PCR products were analyzed by electrophoresis on $1 \%$ agarose gel against a standard DNA Ladder (Fermentas, Germany), in 1X TBE buffer and visualized using the ethidium bromide staining on UV transilluminator. The PCR products were then purified from the agarose gel using QIAquick gel extraction kit (Qiagen, Germany) according to the manufacturer's recommendations and then DNA concentration was measured by spectrometry at OD260 and OD280 using Nanodrop 2000 (Thermo Scientific, USA). The purified DNA was ligated into pTG19-t vector by using T/A PCR product cloning kit (Fermentas, Germany).

\section{Cloning of GRA14 Gene}

The PCR product was cloned into the pTG19 vector via T/A cloning method using the PCR cloning kit (Fermentas, Germany) according to the manufacturer's instructions. Then the pTGRA14 was transformed in E. coli TOP1O competent 
cells (Invitrogen) by calcium chloride method and dispensed on Luria-Bertani (LB) medium (HiMedia, Mumbai, India) agar plates containing Ampicillin (50 mg/L). Bacterial colonies were screened by agar plate containing X-gal (Sigma, USA) and IPTG (Sigma, USA) to discriminate between recombinant (white) and non-recombinant (blue) plasmid containing ones. ${ }^{25,26}$ Recombinant plasmids were detected by blue/white colonies screening method and were confirmed by rusconis test which was applied by Rast et al. ${ }^{27}$ For the rusconis test a white colony was picked up and mixed with 12 $\mu \mathrm{L}$ rusconis solution, centrifuged at $12000 \mathrm{rpm}$ for 2 minutes. Eight microliters of supernatant was electrophoresed in $1 \%$ agarose and visualized after staining with ethidium bromide. ${ }^{27}$ After selecting recombinant clones, the plasmid DNA was extracted from cells cultured overnight with shaking at 250 $\mathrm{rpm}$ at $37^{\circ} \mathrm{C}$ by using the Miniprep plasmid purification kit (Bioneer, Germany) following the manufacturer's instructions. The selected recombinant plasmids were verified by PCR, restriction digestion with SacI and NotI restriction enzymes (Fermentas, USA) and sequenced.

Construction of the Recombinant Expression Plasmid

The pTG19vector carrying the GRA14 gene and the eukaryotic expression vector pET32a (+) (Invitrogen, USA) were digested by SacI and NotI restriction enzymes. After thermal inactivation of the restriction enzymes and analysis by LMP agarose gel electrophoresis, the linearized pET32a $(+)$ plasmid and the GRA14 gene were extracted from the \%1 agarose gel by agarose gel DNA extraction kit (Bioneer, Germany). The purified linear vector and insert were subjected to ligation reaction using T4 DNA ligase (Roche, Germany), generating the pET32a-GRA14 plasmid. E. coli TOP1O competent cells were transformed with $2 \mu \mathrm{L}$ of ligation product.

Transformed E. coli cells were selected on LB medium agar plates containing ampicillin $(50 \mathrm{mg} / \mathrm{L})$. Several colonies were assayed by colony PCR and Rusconis using specific primers. ${ }^{25,27}$ After selecting recombinant clones, the plasmid DNA was extracted from the cells cultured overnight by using the Miniprep plasmid isolation kit (Bioneer, Germany) and confirmed by PCR, restriction-enzyme digestion, followed by DNA sequencing.

Ethical Considerations

Current study does not contain any studies with human participants or animals.

\section{Results}

Cloning and Verification of pTG19-GRA14 Transformation Genomic DNA of RH strain of T. gondii was subjected to PCR to amplify GRA14 gene fragment. PCR products revealed a 1227 bp band on agarose gel (Figure 1).

After ligation of gene fragments to plasmids, transformation of plasmids into competent $E$. coli cells and screening of colonies consisted of recombinant plasmid.

Both white and blue bacterial colonies appeared on the ampicillin-LB agar medium following an overnight cultivation of TOP10 competent cells in exposure to the constructed pTG19-GRA14 recombinant plasmids. However, more than
$90 \%$ of the colonies were white, which indicated successful transformation of pTG19-GRA14 recombinant plasmids into the TOP10 hosts. Several transformed colonies were analyzed by colony PCR with the SAG3 gene specific primers and rusconis (Figure 2).

In addition, agarose gel electrophoresis analysis on plasmids extracted from blue and white colonies exhibited $1227 \mathrm{bp}$ bands of GRA14 gene, which indicated that white colonies had received pTG19-GRA14 recombinant plasmids through successful transformation (Figure 2).

The recombinant plasmid was analyzed by restriction enzyme and rusconis also the resulting fragments were compared with molecular weight marker. Results of agarose gel electrophoresis analysis on constructed pTG19-GRA14 recombinant plasmids following restriction enzymatic digestion revealed two different bands, the first band, which was heavier, indicating linear plasmids and the second, a lighter 1227 bp band, indicating the GRA14 gene (Figure 3 ). These findings confirmed that the GRA14 gene was successfully cloned into pTG19 plasmids.

Subcloning and Gene Sequencing of GRA14 Gene

After the confirmation of a recombinant pTG19-GRA14 plasmid, the recombinant plasmid was isolated from white

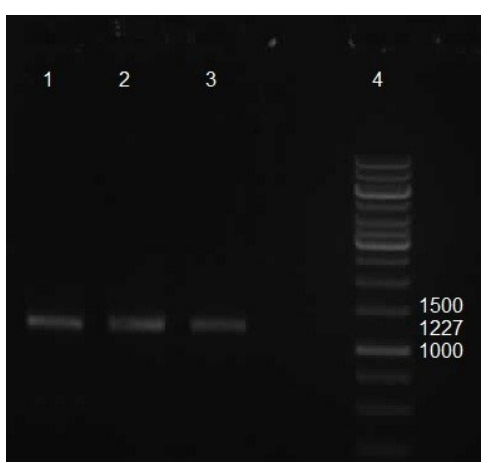

Figure 1. PCR Product on 1\% Agarose Gel Electrophoresis. Lanes 1, 2, 3: GRA14 gene with 1127 bp amplified by PCR; Lane 4: DNA ladder (1 kbp).

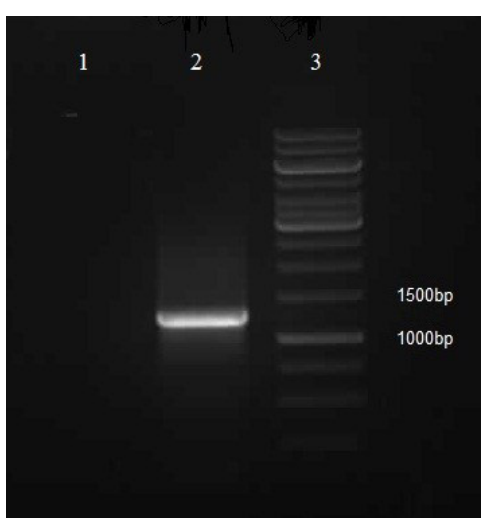

Figure 2. Electrophoresis of PCR Product of pT-GRA14 Plasmid. Lane 1: PCR product of non-recombinant pTG19 plasmid extracted from blue colonies (without band): Lane 2: PCR product of recombinant pT-GRA14 plasmid showing an approximate 1227 bp band; Lane 3: DNA ladder (1 kbp). 


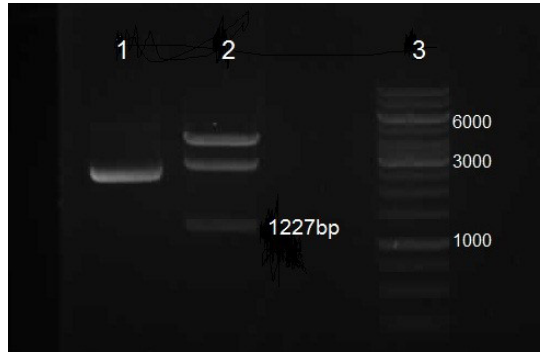

Figure 3. Gel Electrophoresis Analysis Cleavage of GRA14 Fragment From Recombinant pT-GRA14 Plasmid. Lane 1: recombinant pTGRA14 non cleavage; Lane 2: recombinant pT-GRA14 plasmid subjected to restriction cleavage showing a 1227 bp GRA14 fragment. Lane 3: DNA ladder (1 kbp).

colonies and digested by SacI and NotI and released fragment (GRA14 gene) subcloned into SacI and NotI digested pET32a expression plasmid. After transformation of E. coli Top10, recombinant plasmids were analyzed using the colony PCR and PCR on the isolated plasmids, rusconis, restriction digestion (Figure 4) and sequencing (Figure 5).

The recombinant plasmid (pET32a-GRA14) was sequenced (Figure 5). The sequencing result was confirmed by comparing with the databases and using basic local alignment search tool (BLAST) Software on NCBI website. The results showed a 100\% homology with me49 and veg strains and 99\% homology with RH strain GRA14 sequence (ref. No XM_002366572, LN714495, and FJ015061). The new gene sequence obtained from GRA14 was recorded with accession number of MH213492 in GenBank. These findings indicated that the reaction conditions were optimized and the designed primers were specific for amplification of the GRA14 gene and had been successfully cloned into pET32a recombinant plasmids.

\section{Discussion}

Toxoplasma gondii is an obligatory intracellular parasite which has a complicated life cycle and attacks almost all nucleated cells. The high incidence and severe or lethal damages of toxoplasmosis clearly indicate the need for the development of a more effective vaccine. ${ }^{28}$ Moreover, in recent years, researchers are trying to improve the serological diagnosis of toxoplasmosis using recombinant proteins.

Therefore, prompt diagnosis, effective treatment and prevention of this parasite is necessary to minimize the harm of this infection in humans and animals. ${ }^{29}$ Because of diagnostic problems and ineffective therapeutic approaches, vaccine development might be one of the important ways for prevention of toxoplasmosis. Therefore, it is critical to generate specific antigens. Recombination is an easy method to access this specific protein. ${ }^{30,31}$ In recent years, many progresses have been achieved in identifying candidate antigens of vaccine which are capable to inducing protective immune response. A number of these antigens were expressed in prokaryotic organisms and after purifying used in diagnostic studies. ${ }^{32,33}$

GRA proteins of T. gondii were first described as secreted antigens, since they were secreted following incubation of

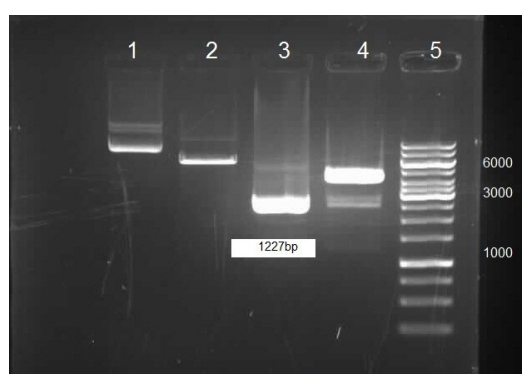

Figure 4. Gel Electrophoresis Analysis Cleavage of GRA14 Fragment From Recombinant pET-GRA14 Plasmids. Lane 1: non-recombinant plasmids; lane 2: recombinant plasmid; Lane 3: recombinant plasmid linear cleavage with Sacl: Lane 4: recombinant pET-GRA14 plasmid subjected to restriction cleavage with Sacl and Notl showing a 1227 bp GRA14 fragment; Lane 5: DNA ladder (1 kbp) .

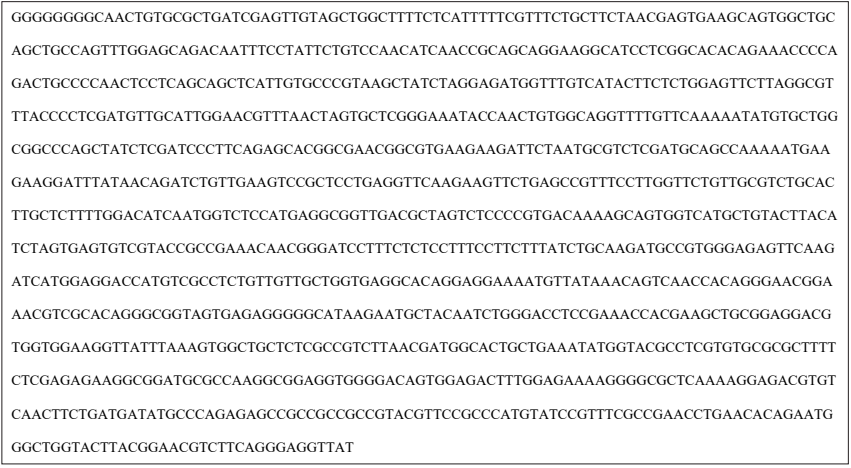

Figure 5. Sequencing Result of the Toxoplasma gondii GRA14 Fragment.

the parasites with serum; it was found that these substances, as regulated secretory proteins, are exported through the Golgi apparatus in response to specific stimulation. ${ }^{34}$ Widely detected and continuously expressed in hosts infected with T. gondii, this has made them as appropriate candidates for tracking the infection and pertinent events. Serological assay is actually the most popular laboratory diagnostic tool for toxoplasmosis designed based on detection of T. gondii GRA proteins. ${ }^{35}$ The present study, for the first time showed clone and subclone GRA14 gene in pTG19 and pET32a prokaryotes expression vector were provided.

The novel dense granule protein GRA14 was secreted into the vacuole, and can be transferred intravascular during infection. Also, GRA14 has an unexpected topology in parasitophorous vacuole membrane. The findings show that C terminus of GRA14, facing the host cytoplasm and its $\mathrm{N}$ terminus facing the vacuolar lumen. Regardless of the possible roles of GRA14, there is no study to evaluate the potential of GRA14 as a vaccine candidate against T. gondii. ${ }^{22,35}$ Therefore, we constructed the recombinant DNA vaccine encoding the GRA14 antigen of T. gondii and evaluated its ability to induce immune response and protective effect in BALB/c mice against acute toxoplasmosis. Several antigens of T. gondii have been used in different vaccination studies and varying results have been reported. ${ }^{36}$

Guo et al cloned a 760bp ROP1 gene fragment into pBV220 expression plasmid and assessed the immune responses 
of Balb/c mice vaccinated by this plasmid. ${ }^{37}$ Meeka et al cloned fragments of ROP1 and SAG1 genes into pRP261 expression plasmid and used the resulting expressed proteins to serological diagnosis of toxoplasmosis in patients suffering from acute and chronic toxoplasmosis. ${ }^{38}$

The successful use of recombinant antigenic proteins for the detection of anti-T. gondii-specific antibodies has been reported by a number of authors. ${ }^{39}$ The recombinant antigens were assessed either separately or by combining several proteins to increase diagnostic sensitivity. ${ }^{39}$ Jalallou et $\mathrm{al}^{40}$ expressed SAG1 in pET32a and used rSAG1 for detection T. gondii specific IgG in human sera by ELISA. Chahed Bel-Ochi et al synthesized and evaluated a whole sequence of the recombinant T. gondii SAG1 antigen for screening of Toxoplasma IgG antibodies. They amplified PCR product and cloned it into the expression vector plasmid pET22b. ${ }^{41}$ Igarashi et al cloned and expressed entire ROP2, GRA5 and GRA7 open reading frames of $T$. gondii $\mathrm{RH}$ strain into pET102/D$\mathrm{TOPO}^{\circ}$ vector which contains thioredoxin and polyhistidine tags at the $\mathrm{C}$ and $\mathrm{N}$ terminal ends and are expressed in E. coli BL21 (DE3). ${ }^{42}$ Mohabati et al developed a recombinant ROP1 protein and assessed its antigenicity against human infected sera by Western blot assay. A 1234 bp DNA fragment of ROP1 gene from T. gondii RH strain was amplified by PCR cloned into pTZ57R/T vector and used pET-15b for its expression. ${ }^{43}$ Eslamirad et al cloned a $760 \mathrm{bp} R O P 1$ gene from T. gondii RH strain into pTZ57R vector and then sub-cloned it in eukaryotic expression vector, pcDNA3. ${ }^{44}$ In another study, Eslamirad et al cloned an 1183 bp ROP1 fragment into pTZ57R/T cloning vector and sub-cloned into pET32a expression plasmid. Wang et al cloned and expressed recombinant proteins GRA1 and GRA7 from T. gondii GT1 strain to use in serodiagnosis of toxoplasmosis in dogs by indirect ELISA. The GRA1 and GRA7 DNA fragments were amplified, and cloned into expression vector $\mathrm{pET}-28$ a to construct recombinant plasmids pET28- GRA1 and pET28-GRA7, which were confirmed by restriction enzymes and sequencing, and were transformed into Escherichia coli BL21 (DE3). ${ }^{45}$ Sadeghiani et al developed recombinant GRA7 antigen and evaluated antigenicity of purified protein in immunoblot using human sera. They used genomic DNA from tachyzoites of T. gondii, RH strain for DNA extraction and amplified a $670 \mathrm{bp}$ fragment encoding amino acids 18 to 236 by PCR. They utilized pTZ57R/T as cloning vector and pET-28b as expression vector. ${ }^{46}$ Hruzik et al recognized TgSUB1 as a potential marker for serodiagnosis of acute toxoplasmosis and used recombinant TgSUB1 in a line blot assay. They isolated RNA from tachyzoites of $T$. gondii strain NTE and used it for cDNA synthesis. The C-terminal fragment of the SUB1 gene (nucleotide positions 1657 to 2316) on the basis of the antigenic index containing amino acid residues 552 to 777 was prepared by PCR amplification and then $660 \mathrm{bp} \mathrm{PCR} \mathrm{product} \mathrm{was} \mathrm{cloned} \mathrm{into}$ pQE-30 expression vector. ${ }^{47}$ In the performed study, the 1227 bp fragment of T. gondii GRA14 gene was cloned into pET32a expression plasmid and ready to produce protein and using of that in diagnostic studies, recombinant vaccine production and immunologic surveys in animal models.

\section{Conclusions}

We successfully cloned GRA14 gene of T.gondii into PTG19 and pET32a plasmid, which was confirmed following restriction enzymatic digestion and gene sequencing. The cloned gene can either be subsequently to produce large amount of the GRA14 recombinant protein for developing serological diagnostic assays, or be used as protein vaccine to stimulate immune responses against $T$. gondii. However, further studies need to be carried out in order to produce recombinant GRA14 protein and to evaluate its immunoreactivity and immunogenicity, as well.

\section{Authors' Contributions}

All authors contributed equally to this research.

\section{Conflict of Interest Disclosures}

The authors declare they have no conflicts of interest.

\section{Acknowledgments}

This study is extracted from a MSc thesis which was approved and supported financially by Baqiyatallah University of Medical Sciences. Also, we would like to give our special thanks to Department of Parasitology and Mycology, Shahid Beheshti University of Medical Sciences for their kind help during this study.

\section{References}

1. Weiss LM, Kim K. Toxoplasma gondii: The model apicomplexan. Perspectives and methods. 1st ed. USA: Academic Press; 2007.

2. Remington JS, McLeod R, Thulliez P, Desmonts G. Toxoplasmosis. In: Remington JS, Klein JO, Wilson CB, Baker CJ, eds. Infectious Diseases of the Fetus and Newborn Infant. Philadelphia: Elsevier Saunders; 2006;947-1091. doi:10.1016/B0-72-160537-0/500335.

3. Bhopale GM. Development of a vaccine for toxoplasmosis: current status. Microbes Infect. 2003;5(5):457-462.

4. Dalton JP, Mulcahy G. Parasite vaccines--a reality? Vet Parasitol. 2001;98(1-3):149-167.

5. Garcia JL, Gennari SM, Navarro IT, et al. Partial protection against tissue cysts formation in pigs vaccinated with crude rhoptry proteins of Toxoplasma gondii. Vet Parasitol. 2005;129(3-4):209217. doi:10.1016/j.vetpar.2005.01.006.

6. Crampton A, Vanniasinkam T. Parasite vaccines: the new generation. Infect Genet Evol. 2007;7(5):664-673. doi:10.1016/j. meegid.2007.06.004.

7. Jacobs D, Vercammen M, Saman E. Evaluation of recombinant dense granule antigen 7 (GRA7) of Toxoplasma gondii for detection of immunoglobulin $\mathrm{G}$ antibodies and analysis of a major antigenic domain. Clin Diagn Lab Immunol. 1999;6(1):24-29.

8. Li S, Maine G, Suzuki Y, et al. Serodiagnosis of recently acquired Toxoplasma gondii infection with a recombinant antigen. J Clin Microbiol. 2000;38(1):179-184.

9. Jongert E, Roberts CW, Gargano N, Forster-Waldl E, Petersen E. Vaccines against Toxoplasma gondii: challenges and opportunities. Mem Inst Oswaldo Cruz. 2009;104(2):252-266.

10. Li S, Galvan G, Araujo FG, Suzuki Y, Remington JS, Parmley S. Serodiagnosis of recently acquired Toxoplasma gondii infection using an enzyme-linked immunosorbent assay with a combination of recombinant antigens. Clin Diagn Lab Immunol. 2000;7(5):781787.

11. Cesbron-Delauw MF. Dense-granule organelles of Toxoplasma gondii: their role in the host-parasite relationship. Parasitol Today. 1994;10(8):293-296.

12. Ching XT, Lau YL, Fong MY, Nissapatorn V, Andiappan $\mathrm{H}$. Recombinant dense granular protein (GRA5) for detection of human toxoplasmosis by Western blot. Biomed Res Int. 2014;2014:690529. doi:10.1155/2014/690529. 
13. Mercier C, Cesbron-Delauw MF, Ferguson DJP. Dense granules of the infectious stages of Toxoplasma gondii: their central role in the host/parasite relationship. In: Soldati D, Ajioka JW, eds. Toxoplasma: Molecular and Cellular Biology. Horizon Scientific Press; 2007.

14. Hughes HP, van Knapen F. Characterisation of a secretory antigen from Toxoplasma gondii and its role in circulating antigen production. Int J Parasitol. 1982;12(5):433-437.

15. Holec-Gasior L, Kur J. Toxoplasma gondii: Recombinant GRA5 antigen for detection of immunoglobulin G antibodies using enzyme-linked immunosorbent assay. Exp Parasitol. 2010;124(3):272-278. doi:10.1016/j.exppara.2009.10.010.

16. Peyron F, Lobry JR, Musset K, et al. Serotyping of Toxoplasma gondii in chronically infected pregnant women: predominance of type II in Europe and types I and III in Colombia (South America). Microbes Infect. 2006;8(9-10):2333-2340. doi:10.1016/j. micinf.2006.03.023.

17. Switaj K, Master A, Skrzypczak M, Zaborowski P. Recent trends in molecular diagnostics for Toxoplasma gondii infections. Clin Microbiol Infect. 2005;11(3):170-176. doi:10.1111/j.14690691.2004.01073.x.

18. Wang Y, Wang G, Ou J, Yin H, Zhang D. Analyzing and identifying novel B cell epitopes within Toxoplasma gondii GRA4. Parasit Vectors. 2014;7:474. doi:10.1186/s13071-014-0474-x.

19. Rome ME, BeckJR, Turetzky JM, Webster P, Bradley PJ. Intervacuolar transport and unique topology of GRA14, a novel dense granule protein in Toxoplasma gondii. Infect Immun. 2008;76(11):48654875. doi:10.1128/iai.00782-08.

20. Nam HW. GRA proteins of Toxoplasma gondii: maintenance of host-parasite interactions across the parasitophorous vacuolar membrane. Korean J Parasitol. 2009;47 Suppl:S29-37. doi:10.3347/ kjp.2009.47.S.S29.

21. Ahmadpour E, Sarvi S, Daryani A, et al. Cloning and sequencing the plasmid encoding dense granule antigen 14 (GRA14) of Toxoplasma gondii RH strain. J Mazandaran Univ Med Sci. 2014;24(112):42-49.

22. Rome ME, BeckJR, Turetzky JM, Webster P, Bradley PJ. Intervacuolar transport and unique topology of GRA14, a novel dense granule protein in Toxoplasma gondii. Infect Immun. 2008;76(11):48654875. doi:10.1128/iai.00782-08.

23. Kalani H, Daryani A, Sharif M, et al. Comparison of eight cell-free media for maintenance of Toxoplasma gondii Tachyzoites. Iran J Parasitol. 2016;11(1):104-109.

24. Sudan V, Tewari AK, Singh H. An insight into the behavior, course and kinetics of acute infection of Toxoplasma gondii human $\mathrm{RH}$ strain in experimentally infected murine model. Iran J Parasitol. 2014;9(1):114-119.

25. Sambrook J, Russell DW. Preparation and transformation of competent E. coli using calcium chloride. CSH Protoc. 2006;2006(1). doi:10.1101/pdb.prot3932.

26. Arab-Mazar Z, Fallahi S, Koochaki A, Mirahmadi H, Tabaei SJ. Cloning, expression and immunoreactivity of recombinant Toxoplasma gondii GRA5 protein. Iran J Microbiol. 2016;8(5):331337.

27. Rasti S, Haghighi A, Kazemi B, Rezaian M. Cloning and characterization of Serine-rich Entamoeba histolytica protein gene from an Iranian E. histolytica Isolate. Pak J Biol Sci. 2006;9(4):654658. doi:10.3923/pjbs.2006.654.658.

28. Hoseinian Khosroshahi K, Ghaffarifar F, D'Souza S, Sharifi $Z$, Dalimi A. Evaluation of the immune response induced by DNA vaccine cocktail expressing complete SAG1 and ROP2 genes against toxoplasmosis. Vaccine. 2011;29(4):778-783. doi:10.1016/j.vaccine.2010.11.012.

29. Wang $Y$, Yin $H$. Research progress on surface antigen 1 (SAG1) of Toxoplasma gondii. ParasitVectors. 2014;7:180. doi:10.1186/17563305-7-180.

30. Johnson AM, Roberts H, Tenter AM. Evaluation of a recombinant antigen ELISA for the diagnosis of acute toxoplasmosis and comparison with traditional antigen ELISAs. J Med Microbiol. 1992;37(6):404-409. doi:10.1099/00222615-37-6-404.

31. Eslamirad Z, Ghaffarifar F, Shojapour M, Khansarinejad B, Sadraei J. A preliminary Study: Expression of Rhoptry Protein 1 (ROP1) Toxoplasma gondii in Prokaryote System. Jundishapur J Microbiol. 2013;6(6):e10089. doi:10.5812/jjm.10089.

32. Nigro M, Gutierrez A, Hoffer AM, et al. Evaluation of Toxoplasma gondii recombinant proteins for the diagnosis of recently acquired toxoplasmosis by an immunoglobulin $\mathrm{G}$ analysis. Diagn Microbiol Infect Dis. 2003;47(4):609-613.

33. Yawen Li \& Huaiyu Zhou. Moving towards improved vaccines for Toxoplasma gondii. Expert Opin Biol Ther. 2018;18(3):273-280. doi:10.1080/14712598.2018.1413086.

34. Arab-Mazar Z, Seyyed-Tabaei SJ, Mirahmadi H. Cloning of dense granular (GRA) 7 gene of Toxoplasma gondii into pTZ57RT vectors. Nov Biomed. 2014;2(4):114-119.

35. Ahmadpour E, Sarvi S, Hashemi Soteh MB, et al. Evaluation of the immune response in BALB/c mice induced by a novel DNA vaccine expressing GRA14 against Toxoplasma gondii. Parasite Immunol. 2017;39(4). doi:10.1111/pim.12419.

36. Bhopale GM. Development of a vaccine for toxoplasmosis: current status. Microbes Infect. 2003;5(5):457-462.

37. Guo H, Chen G, Zheng H, Zhou Y, Lu F. [Immune responses in mice vaccinated with recombinant plasmid pcDNA3 containing ROP1 gene from Toxoplasma gondii]. Zhongguo Ji Sheng Chong Xue Yu Ji Sheng Chong Bing Za Zhi. 1999;17(6):334-337.

38. Meek B, Diepersloot RJ, van Gool T, Speijer D, Peek R. Igm recognition of recombinant Toxoplasma gondii antigens by sera of acutely or latently infected humans. Diagn Microbiol Infect Dis. 2003;45(1):45-52.

39. Holec-Gasior L, Kur J, Hiszczynska-Sawicka E. GRA2 and ROP1 recombinant antigens as potential markers for detection of Toxoplasma gondii-specific immunoglobulin G in humans with acute toxoplasmosis. Clin Vaccine Immunol. 2009;16(4):510-514. doi:10.1128/cvi.00341-08.

40. Selseleh MM, Keshavarz H, Mohebali M, et al. Production and evaluation of Toxoplasma gondii recombinant surface antigen 1 (SAG1) for serodiagnosis of acute and chronic toxoplasma infection in human sera. Iran J Parasitol. 2012;7(3):1-9.

41. Chahed Bel-Ochi N, Bouratbine A, Mousli M. Enzyme-linked immunosorbent assay using recombinant SAG1 antigen to detect Toxoplasma gondii-specific immunoglobulin G antibodies in human sera and saliva. Clin Vaccine Immunol. 2013;20(4):468473. doi:10.1128/cvi.00512-12.

42. Igarashi M, Kano F, Tamekuni K, et al. Toxoplasma gondii: cloning, sequencing, expression, and antigenic characterization of ROP2, GRA5 and GRA7. Genet Mol Res. 2008;7(2):305-313.

43. Mohabati R, Babaie J, Amiri S, et al. Expression and Purification of Recombinant ROP1 of Toxoplasma gondii in Bacteria. Avicenna J Med Biotechnol. 2013;5(4):227-233.

44. Eslamirad Z, Ghorbanzadeh B, Hajihossein R, et al. Cloning of 1183 bp Fragment from Rhoptry Protein I (ROPI) Gene of Toxoplasma gondii $(\mathrm{RH})$ in Expression Prokaryote Plasmid PET32a. Zahedan J Res Med Sci. 2013;15(10):32-36.

45. Wang Z, Ge W, Huang SY, Li J, Zhu XQ, Liu Q. Evaluation of recombinant granule antigens GRA1 and GRA7 for serodiagnosis of Toxoplasma gondii infection in dogs. BMC Vet Res. 2014;10:158. doi:10.1186/1746-6148-10-158.

46. Sadeghiani G, Zare M, Babaie J, et al. Heterologous production of dense granule GRA7 antigen of Toxoplasma gondii in Escherichia coli. Southeast Asian J Trop Med Public Health. 2009;40(4):692700 .

47. Hruzik A, Asif AR, Gross U. Identification of Toxoplasma gondii SUB1 antigen as a marker for acute infection by use of an innovative evaluation method. J Clin Microbiol. 2011;49(7):24192425. doi:10.1128/jcm.00464-11. 